\title{
Editorial Note: Machine Learning for Signal Processing
}

Published online: 20 February 2018

(C) Springer Science+Business Media, LLC, part of Springer Nature 2018

Journal of Signal Processing Systems gratefully acknowledges the editorial work of the scholars listed below on the special issue entitled "Machine Learning for Signal Processing."

Dr. Murat Akcakaya

Electrical and Computer Engineering Department

University of Pittsburgh

Pittsburgh, Pennsylvania 15261

USA

akcakaya@pitt.edu

Dr. Serdar Kozat

Department of Electrical and Electronics Engineering

Bilkent University

06800 Ankara

Turkey

kozat@ee.bilkent.edu.tr 